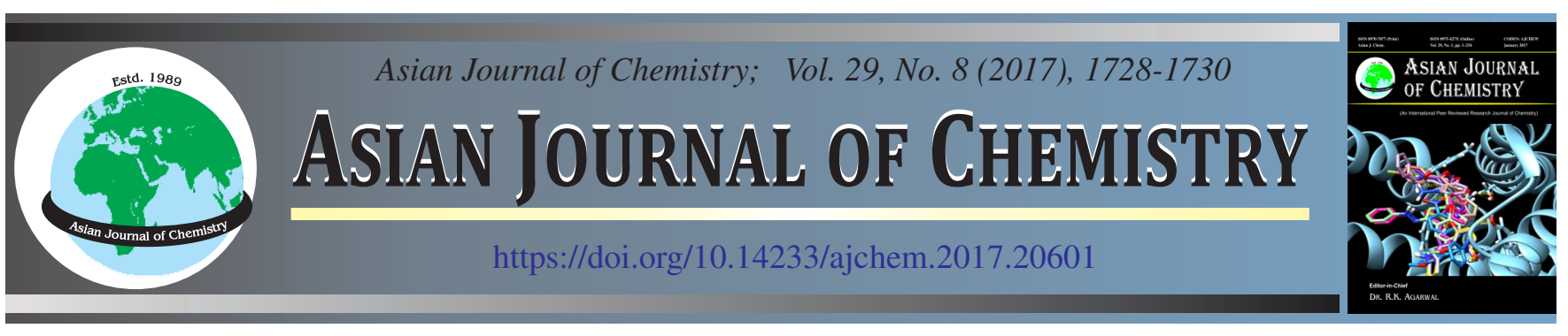

\title{
Transition Metal Complexes of 3,5-Dihydroxy-2-naphthoic Acid and its Nano Metal Oxides: Synthesis and Characterization
}

\author{
Arunadevi Natarajan ${ }^{*}$, Kanchana Ponnuswamy and Kamatchi Ayyasamy
}

Department of Chemistry, PSGR Krishnammal College for Women, Coimbatore-641 004, India

*Corresponding author: E-mail: arunadevi@psgrkc.ac.in; arunadevi_chem@yahoo.co.in

\begin{abstract}
Synthesis of $\mathrm{Cd}(\mathrm{II}), \mathrm{Cu}(\mathrm{II}), \mathrm{Mn}(\mathrm{II})$ and $\mathrm{Zn}(\mathrm{II})$ complexes are achieved by adding hydrazine hydrate and 3,5-dihydroxy-2-naphthoic acid in the ratio 1:4 to the corresponding metal nitrates. The synthesized complexes are characterized by elemental analysis, IR, UV, TG-DTA and XRD analysis. The nano metal oxides are obtained by decomposing the complexes at $800{ }^{\circ} \mathrm{C}$ in the muffle furnace. The nano metal oxides are characterized by IR and XRD studies. The surface morphology and quantative analysis of metal oxides were determined by using SEM analysis. The shape of nano zinc oxide is rock like hexagonal structure while that of nano Mn oxide is rod like structure which was confirmed by transmission electron microscopy analysis.
\end{abstract}

Keywords: SEM images, Hexagonal structures, TEM images, TG-DTA.

\section{INTRODUCTION}

The hydroxynaphthoate ion has a variety of dentation modes in which both carboxylate and phenolic oxygen atoms participate [1-4]. Lanthanide complexes [5,6] with ortho substituted naphthoic acid show that the hydroxynaphthoate ion is monodentate, coordinated to the metal through the carboxyl group. A study of $(\mu-\mathrm{L})_{4}\left[\mathrm{Nd}\left(\mathrm{H}_{2} \mathrm{O}\right)(\mathrm{EtOH}) \mathrm{L}\right]_{2} \cdot 2 \mathrm{H}_{2} \mathrm{O} \cdot 2 \mathrm{EtOH}$, ( $\mathrm{L}$ is 1-hydroxy-2-naphthoate ligand) indicates that, two ligands act as bidentates and the two other as terdentates [7]. Gupta et al. [8] have prepared complexes of Fe, Ti, V, Al, Cu and Be using hydroxynaphthoic acid as a chelating agent and have studied the thermodynamic properties of complex of $\mathrm{Fe}$ (III) also with the same acid in ethanolic solution [9]. These complexes were found to decompose to their oxides with the intermediate formation of the respective naphthoates [10]. A detailed investigation of photophysics of 1-hydroxy-2naphthoic acid has been carried out [11]. The investigation of structure of magnesium salts of 1-hydroxy-2-naphthoic acid was also reported [12]. These molecules are used as chelating agents, fluorescent indicators and the manufacturing of dyestuffs.

A study of isomeric hydroxynaphthoic acid with transition metals and hydrazine has not been attempted so far. Hence, it was decided to prepare the transition metal complexes with 3,5-dihydroxy-2-naphthoic acid and hydrazine and to study various spectral properties.

\section{EXPERIMENTAL}

3,5-Dihydroxy naphthoic acid was purchased from Sigma Aldrich. All other reagents were of AR grade and the solvents were purified by using standard methods. Micro analysis of $\mathrm{C}, \mathrm{H}$ and $\mathrm{N}$ were obtained using elemental analysis. The IR spectra in the range $4000-400 \mathrm{~cm}^{-1}$ were obtained with $\mathrm{KBr}$ pellet using ATR Shimadzu model spectrometer. The UV spectra were run on Lad India UV-visible spectrometer using nujol mull. The TG-DTA analysis was obtained on PerkinElmer STA 600 thermal analyzer. The XRD pattern was taken with X-ray diffractometerBurker advanced D8 X-ray at room temperature using $\mathrm{Cu} \mathrm{K}_{\alpha}$ radiation over a wide range of Bragg angles. The surface morphologies of $\mathrm{ZnO}$ and $\mathrm{MnO}$ nanoparticles were observed by using SEM at room temperature. To confirm the size of the particles, further the metal oxides was analyzed with JEOL JEM 2100 high resolution transmission electron microscope (HRTEM).

Synthesis of $\left[\mathrm{M}\left(\mathrm{C}_{11} \mathrm{H}_{6} \mathrm{O}_{6}\right)\left(\mathrm{N}_{2} \mathrm{H}_{4}\right)_{2} \cdot 2 \mathrm{H}_{2} \mathrm{O}\right.$ where $\mathrm{M}=$ $\mathbf{C d}(\mathrm{II}), \mathbf{C u}(\mathrm{II}), \mathbf{M n}(\mathrm{II})$ and $\mathbf{Z n}(\mathrm{II})$ : To the solution of 3,5dihydroxy-2-naphthoic acid $(0.2049,0.001 \mathrm{~mol}), 10 \%$ hydrazine hydrate was added. The solution was kept over the water bath for about 30 min to get transparent, homogeneous solution and the $\mathrm{pH}$ of the ligand solution was found to be 9 .

The metal nitrate [Cd(II), $\mathrm{Cu}(\mathrm{II}), \mathrm{Mn}(\mathrm{II})$ and $\mathrm{Zn}(\mathrm{II})]$ solution $\left(0.001 \mathrm{mmol}\right.$ in $\left.10 \mathrm{~mL} \mathrm{H}_{2} \mathrm{O}\right)$ was then added to the prepared ligand solution, with slow and constant stirring. The 
reaction mixture was heated over a water bath for $2 \mathrm{~h}$ and kept as such in a dark room for $24 \mathrm{~h}$. A polycrystalline substance which obtained was washed with alcohol and dried.

Synthesis of nano $\mathrm{Zn}$ and Mn oxide particles: The metal oxides were synthesized by incineration of the complex in muffle furnace at $800{ }^{\circ} \mathrm{C}$ for $5 \mathrm{~h}$. The nano metal oxides obtained by this method are free from organic impurities and expected to be homogeneous.

\section{RESULTS AND DISCUSSION}

The elemental analysis data were in good agreement with the calculated values and shows the formation of 1:1:2 [M:A:B] ratio. The hydrazine content was determined by titrating against $\mathrm{KIO}_{3}(0.025 \mathrm{~mol} / \mathrm{L})$ under Andrew's condition. Metal content were estimated by titrating with standard EDTA $(0.01 \mathrm{~mol} / \mathrm{L})$ after decomposing $60 \mathrm{mgm}$ of the complex with $1: 1$ nitric acid for three times to destroy the organic content [13].

IR spectra: The IR spectra of the free ligand were shifted upon complex formation. The ligand shows a band of $\mathrm{OH}$ group at $3300 \mathrm{~cm}^{-1}$ and it disappeared in the complex. This indicates the deprotonation of the hydroxyl group and coordinates to the metal atom through oxygen. Two new bands in the region $762-740 \mathrm{~cm}^{-1}$ and $3311-3200 \mathrm{~cm}^{-1}$ are assigned to $\mathrm{v}(\mathrm{N}-\mathrm{N})$ and $v(\mathrm{~N}-\mathrm{H})$ respectively [14]. The appearance of new band in the range of $3379-3278 \mathrm{~cm}^{-1}$ is due to $\mathrm{O}-\mathrm{H}$ stretching vibration which indicates the presence of lattice water (Table-1).

Thermal studies: The simultaneous TG-DTA (Table-2) was recorded for the complexes in order to explore their thermal stability. The TG-DTA curves of the complexes of Cd(II), Mn(II), $\mathrm{Zn}$ (II) and $\mathrm{Cu}$ (II) were shown in Fig. 1. All the complexes show three stage decomposition patterns. Initially it showed endothermic band around $77-120{ }^{\circ} \mathrm{C}$ with a mass corresponding to loss of water molecules in the complex. Secondly, it

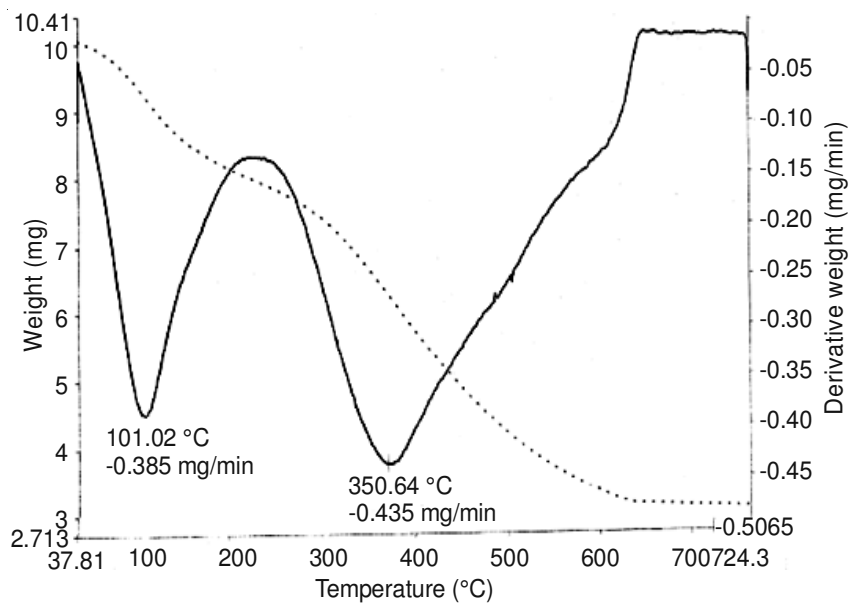

Fig. 1. TG-DTA curve of $\left[\mathrm{Cd}\left(\mathrm{C}_{11} \mathrm{H}_{8} \mathrm{O}_{4}\right)\left(\mathrm{N}_{2} \mathrm{H}_{4}\right)_{2}\right] \cdot 2 \mathrm{H}_{2} \mathrm{O}$ shows strong exothermic band around $130-300^{\circ} \mathrm{C}$ which may be due to the formation of unstable metal naphthoate. In the final step it decomposes continuously leading to the formation of corresponding metal oxides in the range of 350-700 ${ }^{\circ} \mathrm{C}$.

TEM: TEM analysis of cross-sectional samples were carried out for the prepared nanometal oxides. It was apparent from the Fig. $2 \mathrm{a}$ and $2 \mathrm{~b}$ that the metal oxides are in good distribution with evenness and there is formation of agglomerates. The SEM images of the metal oxides were shown in Fig. 3. Fig. 4 represents EDX spectra of the zinc oxide which is used to determine the composition of the metal oxide. The strong signals from Co confirm the presence of metals in nano oxide.

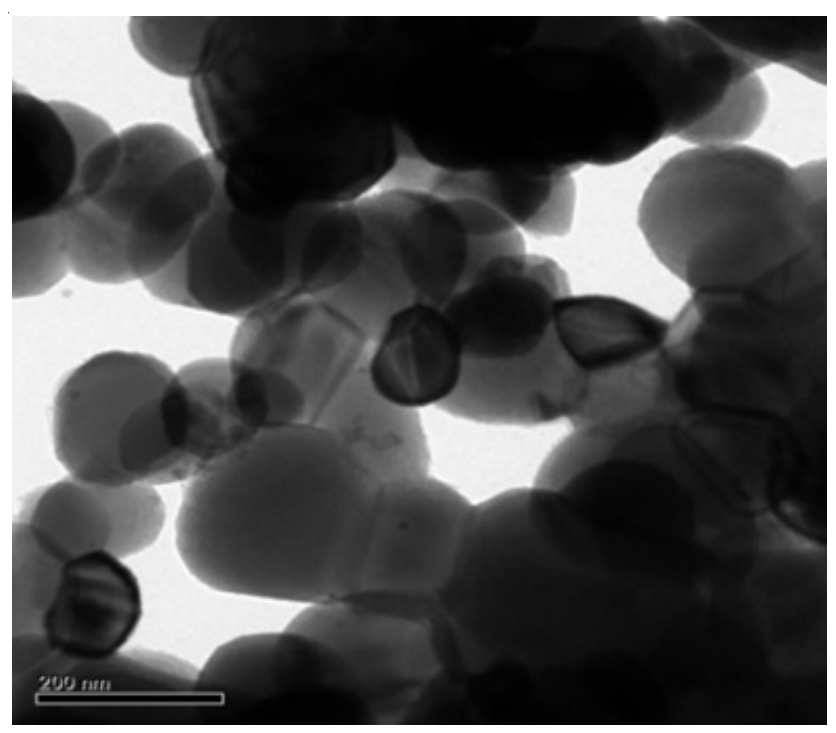

Fig. 2a. TEM image of zinc oxide

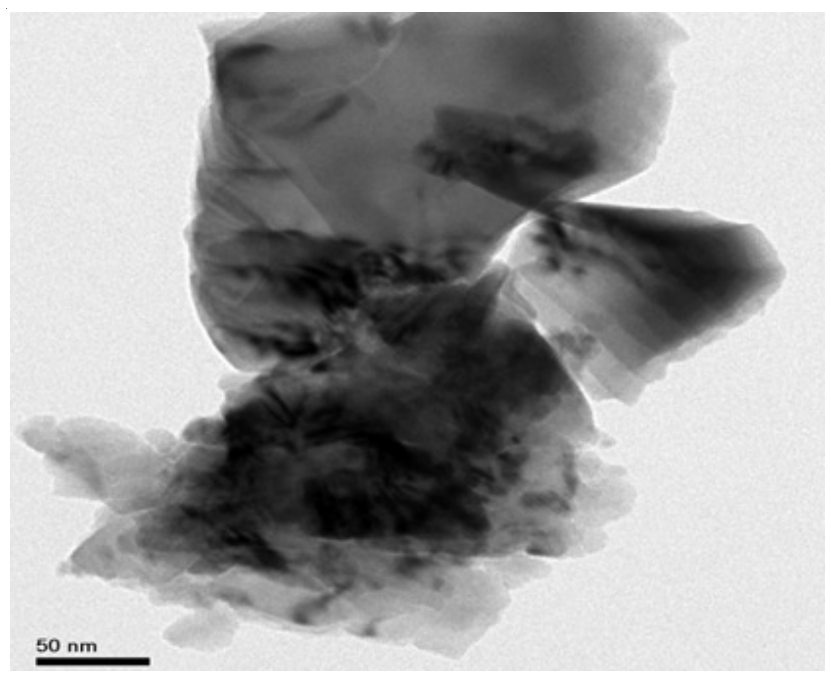

Fig. 2b. TEM image of manganous oxide

\begin{tabular}{llccccccccc}
\multicolumn{10}{c}{ TABLE-1 } \\
\hline \multicolumn{10}{c}{ PHYSICO-CHEMICAL AND IR DATA OF THE COMPLEXES } \\
\hline \multicolumn{1}{c}{ Complexes } & \multicolumn{1}{c}{ Colour } & $\begin{array}{c}\text { Yield } \\
(\%)\end{array}$ & $\begin{array}{c}\text { Decomposition } \\
\text { temperature }\end{array}$ & $v(\mathrm{O}-\mathrm{H})$ & $v\left(\mathrm{H}_{2} \mathrm{O}\right)$ & $v(\mathrm{~N}-\mathrm{H})$ & $v_{\text {asym }}(\mathrm{COO})$ & $v_{\text {sym }}(\mathrm{COO})$ & $v(\mathrm{~N}-\mathrm{N})$ \\
\hline 3,5-Dihydroxy-2-naphthoic acid & Yellow & - & 272 & 3300 & - & - & 1663 & 1517 & - \\
{$\left[\mathrm{Mn}\left(\mathrm{C}_{11} \mathrm{H}_{8} \mathrm{O}_{4}\right)\left(\mathrm{N}_{2} \mathrm{H}_{4}\right)_{2}\right] \cdot \mathrm{H}_{2} \mathrm{O}$} & Light brown & 75 & 120 & - & 3379 & 3300 & 1500 & 1421 & 750 \\
{$\left[\mathrm{Cu}\left(\mathrm{C}_{11} \mathrm{H}_{8} \mathrm{O}_{4}\right)\left(\mathrm{N}_{2} \mathrm{H}_{4}\right)_{2}\right] \cdot \mathrm{H}_{2} \mathrm{O}$} & Blue & 70 & 172 & - & 3752 & 3311 & 1561 & 1436 & 762 \\
{$\left[\mathrm{Zn}\left(\mathrm{C}_{11} \mathrm{H}_{8} \mathrm{O}_{4}\right)\left(\mathrm{N}_{2} \mathrm{H}_{4}\right)_{2}\right] \cdot 2 \mathrm{H}_{2} \mathrm{O}$} & Dull brown & 75 & 165 & - & 3330 & 3200 & 1591 & 1545 & 740 \\
{$\left[\mathrm{Cd}\left(\mathrm{C}_{11} \mathrm{H}_{8} \mathrm{O}_{4}\right)\left(\mathrm{N}_{2} \mathrm{H}_{4}\right)_{2}\right] \cdot 2 \mathrm{H}_{2} \mathrm{O}$} & White & 85 & 174 & - & 3278 & 3200 & 1550 & 1421 & 750 \\
\hline
\end{tabular}




\begin{tabular}{|c|c|c|c|c|c|}
\hline \multirow{4}{*}{ Complexes } & \multicolumn{4}{|c|}{$\begin{array}{c}\text { TABLE-2 } \\
\text { THERMAL ANALYSIS OF THE COMPLEXES }\end{array}$} & \multirow{4}{*}{ Nature of decomposition } \\
\hline & \multirow{3}{*}{$\begin{array}{c}\text { DTA peak } \\
\text { temperature } \\
\left({ }^{\circ} \mathrm{C}\right)\end{array}$} & \multicolumn{3}{|c|}{ Thermogravimetry } & \\
\hline & & \multirow{2}{*}{$\begin{array}{l}\text { Temperature } \\
\text { range }\left({ }^{\circ} \mathrm{C}\right)\end{array}$} & \multicolumn{2}{|c|}{ Moss loss (\%) } & \\
\hline & & & Found & Calculated & \\
\hline \multirow{3}{*}[\mathrm{Cu}(\mathrm{C}_{11}\mathrm{H}_{8}\mathrm{O}_{4})(\mathrm{N}_{2}\mathrm{H}_{4})_{2}]{$\cdot \mathrm{H}_{2} \mathrm{O}$} & 88 & $40-160$ & 5 & 59.15 & Dehydration \\
\hline & 248 & $190-250$ & 20 & 19.29 & Dehydration \\
\hline & 335 & $350-600$ & 75 & 77.36 & Formation of $\mathrm{CuO}$ \\
\hline \multirow{3}{*}[\mathrm{Zn}(\mathrm{C}_{11}\mathrm{H}_{8}\mathrm{O}_{4})(\mathrm{N}_{2}\mathrm{H}_{4})_{2}]{$\cdot 2 \mathrm{H}_{2} \mathrm{O}$} & 77.27 & $50-150$ & 10 & 9.74 & Dehydration \\
\hline & & $160-350$ & 30 & 27.05 & Formation of metal naphthoate \\
\hline & & $390-600$ & 78 & 77.87 & Formation of $\mathrm{ZnO}$ \\
\hline \multirow{3}{*}[\mathrm{Cd}(\mathrm{C}_{11}\mathrm{H}_{8}\mathrm{O}_{4})(\mathrm{N}_{2}\mathrm{H}_{4})_{2}]{$\cdot 2 \mathrm{H}_{2} \mathrm{O}$} & 120 & $50-130$ & 9 & 8.64 & Dehydration \\
\hline & 245 & $150-300$ & 25 & 24.00 & Formation of metal naphthoate \\
\hline & 430 & $350-650$ & 80 & 8.00 & Metal oxide formation \\
\hline \multirow{2}{*}[\mathrm{Mn}(\mathrm{C}_{11}\mathrm{H}_{8}\mathrm{O}_{4})(\mathrm{N}_{2}\mathrm{H}_{4})_{2}]{$\cdot \mathrm{H}_{2} \mathrm{O}$} & 123 & $80-140$ & 5 & 60.00 & Dehydration \\
\hline & 300 & $140-650$ & 78 & 76.00 & Metal oxide formation \\
\hline
\end{tabular}

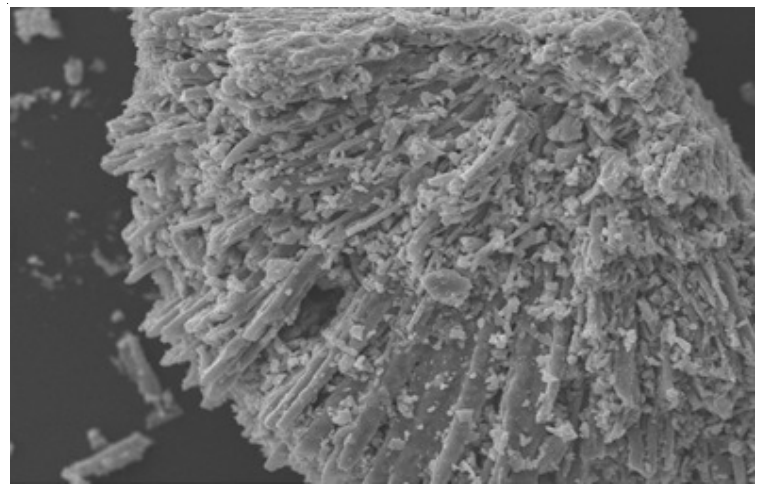

Fig.3a. SEM image of zinc oxide

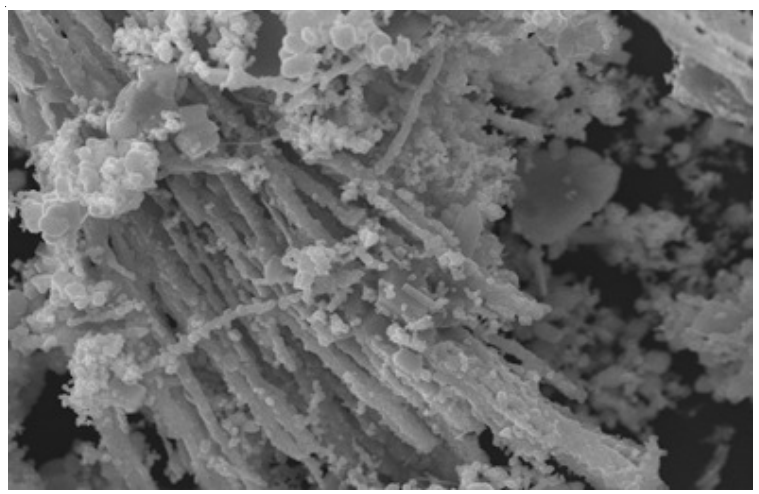

Fig. 3b. SEM image of manganous oxide

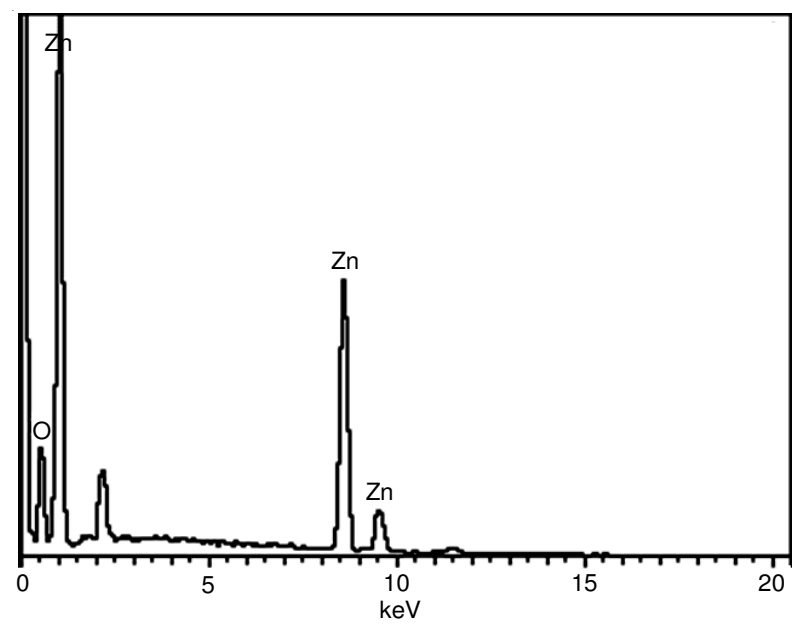

Fig. 4. EDX spectra of zinc oxide

\section{ACKNOWLEDGEMENTS}

The authors are grateful to University Grant Commission, New Delhi, India for the financial support for this project work.

\section{REFERENCES}

1. S.A. Elsayed, A.M. El-Hendawy, I.S. Butler and S.I. Mostafa, J. Mol. Struct., 1036, 196 (2013);

https://doi.org/10.1016/j.molstruc.2012.09.018.

2. J.-Y. Miao, Synth. React. Inorg. Metal Org. Nano Metal Chem., 42, 1463 (2012);

https://doi.org/10.1080/15533174.2012.684229.

3. N. Arunadevi and S. Vairam, E-J. Chem., 6S1, S413 (2009); https://doi.org/10.1155/2009/937216.

4. E. Casassas, R. Tauler and G. Fonrodona, Polyhedron, 7, 1335 (1988); https://doi.org/10.1016/S0277-5387(00)80382-4.

5. Y.H. Deshpande and V. Ramachandra Rao, J. Inorg. Nucl. Chem., 35, 3626 (1973);

https://doi.org/10.1016/0022-1902(73)80377-X.

6. Y.H. Deshpande, D.V. Jahagirdar and V.R. Rao, J. Inorg. Nucl. Chem., 37, 1761 (1975);

https://doi.org/10.1016/0022-1902(75)80313-7.

7. Y. Ohki, Y. Suzuki, T. Takeuchi, M. Shimoi and A. Ouchi, Bull. Chem. Soc. Jpn., 59, 1015 (1986);

https://doi.org/10.1246/bcsj.59.1015.

8. S.L. Gupta and R.N. Soni, J. Indian Chem. Soc., 43, 331 (1966).

9. A.N. Pant, R.N. Soni and S.L. Gupta, J. Inorg. Nucl. Chem., 34, 2951 (1972);

https://doi.org/10.1016/0022-1902(72)80605-5.

10. N. Kavitha and P.V. Anatha Lakshmi, J. Saudi Chem. Soc., 21S1, S457 (2017); https://doi.org/10.1016/j.jscs.2015.01.003.

11. H. Misra, G. Maheswary, H.B. Tripathi and N. Sathyamurthy, J. Phys. Chem. A, 109, 2746 (2005);

https://doi.org/10.1021/jp0461091.

12. F. Huang and W.D. Song, Acta Cryst. E, 64, m552 (2008); https://doi.org/10.1107/S1600536808006351.

13. A.I. Vogel, A Text Book of Quantitative inorganic Analysis, Longmans Green, London (1975).

14. A. Braibanti, F. Dallavalle, M.A. Pellinghelli and E. Leporati, Inorg. Chem., 7, 1430 (1968); https://doi.org/10.1021/ic50065a034. 